\title{
Recognition and Appreciation and the Moderating Role of Self-esteem on Job Satisfaction and Performance among IT Employees in Melaka
}

\author{
Olurotimi Adebayo Shonubi ${ }^{1}$, Norida Abdullah ${ }^{2}$, Rahman Hashim ${ }^{1}$ and Norhidayu Binti Ab Hamid ${ }^{1}$ \\ 1. Institute of Technology Management and Entrepreneurship, Universiti Teknikal Malaysia Meleka, Hang Tuah Jaya, Durian \\ Tunggal, Melaka 76100, Malaysia \\ 2. Centre for Languages and Human Development, Durian Tunggal, Melaka 76100, Malaysia
}

\begin{abstract}
The purpose of this study is to explore and examine employees' perceptions of recognition and appreciation among Telekom Malaysia (TM) employees in Melaka and the psychological influence it has on their job satisfaction, performance, productivity, and commitment towards the organizational goals. According to one of the laws of psychology which "says if you want someone to repeat a behavior, you should positively recognize the behavior immediately”. Thus, it has been positively affirmed that every human being like to be recognized and appreciated because it is an innate aspiration. Conversely, even though there is nothing complex about recognition and appreciation, studies has found that these items consistently receive the lowest ratings from employees. Furthermore, research conducted over so many eras constantly and consistently discovered that people care about fair treatment, thus, recognition and appreciation of employees must be done appropriately and timely in order for the program to be effective and efficient and achieve its full objective and set goal of motivation. The constructs that will be used in this study will be operationalized using previously-validated and originally developed measures with little or no modifications where necessary to suit the present research context while the primary data of this research will be analyzed using AMOS software.
\end{abstract}

Key words: Recognition, appreciation, self-esteem, job satisfaction, job performance, IT employees, psychological effect.

\section{Introduction}

In one of recognition study by Nghi and Yecenia [1] on the IT employees, the study discovered that successful practices, where providing a persistent and accurate feedback to IT staff, recognition and noticeable rewards develops the teamwork spirit, and makes an achievement of balance between an individual's professional and personal identity. Recognition and appreciation systems are an important part of the change that is necessary for any transformation to be effective. A thorough rethinking and restructuring of recognition and appreciation practices which are aligned with new organizational goals and culture will give companies the focused

Corresponding author: Olurotimi Adebayo Shonubi, doctor of philosophy (student), research fields: industrial counseling and human resources development. energy they will need to succeed in challenging times. Those companies that use relevant compensation and rewards as strategic resource tools will be able to realize the tremendous potential of their employees, working together.

This purpose of this study is to explore employees' perceptions of recognition and appreciation among IT employees in Melaka and the psychological influence it has on their job satisfaction, performance, productivity, and commitment towards the organizational goals. Research consistently finds that people care about fair treatment. When individuals perceive that they are treated fairly, they express greater satisfaction with social relationships [2]. This is suggests that organizations and their systems and processes are vulnerable to the power of human perceptions. Considering that human wants and needs are unlimited 
and insatiable and also putting into consideration that employee motivation is a basic psychological process.

Limaye and Sharma [3] exploration on employees motivation, stated that today's workforce is much more articulate about their needs and wants as well as desiring the best of everything; competitive salaries, comfortable lifestyles, job security, career enhancement options, work-life balance. As human, our wants and need are unlimited and can never be satisfied, acknowledging this fact, this is why organizations need to have well-defined philosophies and strategies which will help them develop innovative, intrinsic ways of motivating and engaging with their employees. While many are struggling to make the difference, some organizations have institutionalized robust practices and effective processes that go a long way in impacting employee perception. Agreeing on Manoko [2]; Cokins [4]; the writer states that if organization make use of the wrong key performance indicators, then the behavior, priorities and decisions of employees and their organization as a whole will not be well aligned with the direction of the executive team.

It is noteworthy to know that an organization can use recognition as a strategic measure to show employees that their contribution to the organization is recognized, and in so doing, influence their motivation and job performance. Manoko [2] the study revealed that organization could improve and encourage the use of effective recognition in the feedback process of the performance management system. The study findings stated further that recognition program could also influence the company to consider a more structured approach to recognition that would enable the high performance culture it strives to attain. Hence, this present research will examine the psychological role recognition and appreciation plays in motivating employees and the moderating role of self-esteem. The study will explore which of these factors, recognition or appreciation, has a greater influence on employee job satisfaction and performance.

\section{Review of the Literature}

One of the reason to motivate an employee through recognition in an organization is to increase the existence of the both the employee and the organization. It was revealed that workplaces are suffering with employees who are unmotivated and overall job satisfaction and work performance is failing [5]. Thus, if the organizations were well educated on how to motivate their employees would be happier and the company as a whole would be more advantageous and valued. Employee recognition can go a long way, and it doesn't need to be costly, or timely. In times when organizations are closely watching expenses, rewards and recognition are a low-cost, effective way of encouraging employees to perform at higher levels [6].

Recognition is said to be an important key to the success of an organization because it helps people understand how their behaviour makes a difference to both their personal and the organization's goals. Recognition, properly communicated, employees feel a greater sense of ownership, accountability, and pride [7]. There is not a more effective way to motivate employees than to achieve the desired goals of the organization. These means should include creating a strong, respectful and supportive relationship between the organization's managers and employees, including a focus on genuine expressions of appreciation for specific employee achievements, service milestones, and day-to-day acknowledgement of performance excellence. Overall, recognition can be summed up by the following: nothing is better than a sincere "thank you for a job well done" [8].

According to a study on employee's recognition by Theresa, it was pointed out that if an organization's recognition program is well structured and effective, it will be a key building block to its human capital management system. Recognition needs to be designed to provide feedback to employees about their strengths and weaknesses, including recommendations on development opportunities that impact career progression for both the employee and the 
organization [9]. Recognition can be used as a tool to identify performance challenges and opportunities and identifying solutions. However, it was concluded that options are only limited by the imaginations and creativity of the individuals who decided to utilize recognition to enhance employee performance. It is up to the management of the organization to ensure that it does not stand in the way of progress.

\subsection{Recognition and Appreciation and Its Significant} Outcome

When a person feel appreciated and valued for his or her contributions in the place of work, it always leads to more spirited innovative environment, increased employee engagement, commitment, less staff turnover, higher customer satisfaction ratings and the organization grows in its sense of purpose [10]. In a similar exploration according to Jeff [11] states that it is everyone aspiration to feel important, yet many organizations manage to make their people feel quite the opposite. It could be seen as a lack of simple appreciation, or a greater focus put on making numbers, and not valuing employees. Some employees might feel like a mere number that no one in any kind of position above them listens to them or even knows they exist, much less work there. Managers who do show some appreciation might not show it in a timely manner, or the rewards given might have little if anything to do with what the employees truly find valuable.

It was suggested by Ajila [12] that for an individual to be motivated in a work situation, there must be a need, which the individual would have to perceive a possibility of satisfying through some reward. If the reward is intrinsic to the job, such desire or motivation is intrinsic. Maheshwari (2011), Seligman and Ajang (2007), Csikzentmihalyi (2000), Seligman (1998), Linder (1998), Kreitner (1995), Buford, Bedeian and Linder (1995), Higgins (1994) [13-18] talked about motivation as "the psychological process that gives behavior purpose and direction, a predisposition to behave in a purposive manner to achieve specific unmet needs, an unsatisfied need, and the will to achieve, respectively.

\subsection{The Moderating Effects of Self-esteem}

Moderator which can also be referred to as independent factor in this study is to give direction of the relationship on the relation between recognition or appreciation and Job Satisfaction and Job Performance. According to Bennet's (2000) research on mediator and moderator variables provide useful information about how, why, or when a phenomenon occurs. For example, "mediator" is often used as if it meant "predictor". A mediator or moderator is a third variable that changes the association between an independent variable and an outcome variable [19]. Thus, consideration of a mediator or moderator allows a more precise description of the relationship between independent and outcome variables. If a researcher fails to consider the possibility of a mediator or moderator effect in the data, a more exact explanation for an outcome may be missed.

\subsection{Moderator as an Independent Variable}

A moderator is an independent variable that affects the strength and/or direction of the association between another independent variable and an outcome variable. The moderator interacts with the independent variable of interest so that the independent variable's association with the outcome variable is stronger or weaker at different levels of the moderator variable. In other words, the association of the independent variable with the outcome variable "depends on" the value (or level) of the moderator variable [20]. A researcher who includes a moderator in the model wants to know "when" the relationship occurs between the independent and outcome variables. Therefore, the researcher is usually more interested in the independent variable than the moderator.

\subsection{Content Theories}

Content theory which includes the work of Maslow; 
Herzberg, explains why human needs change with time. Content theories explain the specific factors that motivate behaviour. However, for this present study, Herzberg two-factor theory and Abraham Maslow theory are the main two theories apply, because their main idea is on non-monetary or rather intrinsic value and it was affirmed that it can be more important source of motivation.

\subsection{Herzberg's Two-Factor Theory}

Herzberg's Two-Factor will be used as the main theory of this study with support of Abraham Maslow hierarchy of needs. These two theories explain the effect of employees' motivation and its psychological outcome. In his theory findings he bifurcates two factors; Hygiene factors (basic pay, job security, friends in the workplace) and Motivational factors (recognition, achievement, advancement, and challenging work) which he says were the key ingredients for an employee's satisfaction at the workplace [21]. Herzberg, suggests that there are factors in a job, which enhances satisfaction when available. These are called intrinsic factors (motivators) but when these factors are absent, no much demotivation would occur.

\subsection{Maslow's Hierarchy of Needs Theory}

Abraham Maslow is considered to be the father of Human Psychology who designed a pyramid to understand the different levels of human motivation. These hierarchical levels from bottom to top were Physiological needs, Security, Social, Esteem and Self-actualisation which corresponded different stages of human motivation [22]. The most important statement by Maslow linking to this research is that 'his hierarchical arrangement didn't actually imply focusing more on the higher needs because they were better, rather the lower needs because without the lower level needs satisfied, the higher level needs didn't appear' [22], meaning that motivation and job satisfaction levels of employees are not static and does not come down to one of the hierarchical needs being either the lowermost (Physiological need) or the topmost (Self-actualisation need) but rather a combination of certain needs depicting certain factors.

\section{Research Hypothesized Model}

Based on previous literatures and content theories, this present study developed a research hypothesized model in order to give this study guidance and direction. As this study aims to survey the psychological influence of recognition and appreciation on employees' job satisfaction and performance among IT employees of Telekom Malaysia (TM). Thus, recognition and appreciation are regarded as endogenous variables; self-esteem as the moderating variable, while job satisfaction and job performance are considered as the exogenous variables for this study. The research model of the study is given in Figure 1.

In this study, cross-sectional study design with an exploratory and descriptive design will be used. According to Sekaran and Bougie [23] and Spector [24] cross sectional study is a study which data are gather just once (days, weeks or months) to answer the research question. However, exploratory and descriptive designs focus on the occurrence of interest, which according to this study, is to find out whether intrinsic motivational package i.e. recognition and appreciation have any psychological influence on IT employees job satisfaction and performance and help in identifying factors that may lead to job satisfaction.

\subsection{Population/Sampling}

This study population from which the sample will be drawn for the study will consists IT employees of Telekom Malaysia. TM is chosen for this study because it is the best sought after internet service provider in Malaysia. Telekom Malaysia Berhad DBA (TM) is Malaysia's leading telecommunications company, with a history dating back to 1946. Beginning as the national telco for fixed line, radio and television 


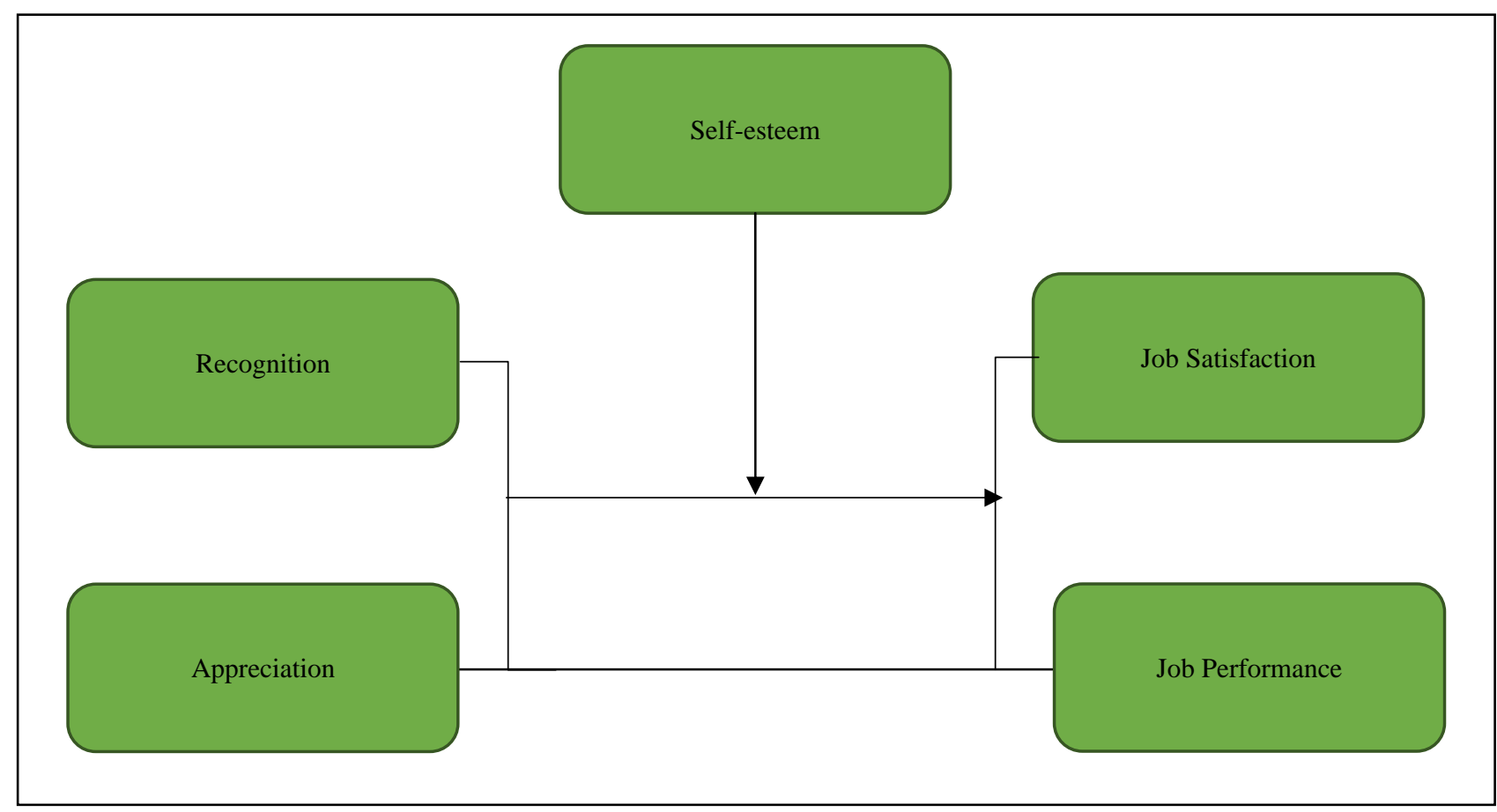

Fig. 1 Research hypothesized model (source: self-construct based on theories).

broadcasting services, it has evolved to become the largest broadband services provider (www.tm.com.my).

\subsection{Sampling Procedure}

Sampling is the process of selecting a sufficient number of the right elements from the population as affirmed by Sekaran and bougie [23] in order to enable the study select appropriate sample and an understanding of its properties or characteristics make it possible for generalization. Sample size should be appropriate for the analysis that is planned [25, 26].

Nevertheless, neglecting the limitations involved, a non-probability sampling design, namely, convenience sampling will be used to obtain require sample size for this study. This study chose convenience sampling method because it will enable the researcher to collect information from members of the population who are most easily accessible and conveniently available to provide the required information $[27,28]$.

\subsection{Instrumentation}

The constructs that will be used in this study will be operationalized using previously-validated and originally developed measures with little or no modifications where necessary to suit the present research context (Table 1). Each of the measures will consists of multiple items that are evaluated by using 5-point Likert scales to elicit participant perceptions that will allow frequency, central tendency, and correlative measures of the responses. The research will be designed in such a way that information about a large number of people will be deduced from responses obtained from a smaller group of subjects. Furthermore, due to the nature of this study respondents, the questionnaire will be translated from English to Bahasa Melayu.

\subsection{Data Analysis Tools}

The primary data of this research will be analyzed using AMOS software. The statistical program that will be used for the analyses and presentation of data in this existing research is the Structural Equation Model (SEM-AMOS). The descriptive statistics will be utilized based on frequency tables and graphical illustrations to provide information on key biographical 
Table 1 Adapted from Steve Burrel [29].

\begin{tabular}{|c|c|c|c|}
\hline Scale & $\begin{array}{l}\text { No. of } \\
\text { Items }\end{array}$ & Adapted from Sources & Operational Definition \\
\hline Recognition & 16 & $\begin{array}{l}\text { The measures for recognition } \\
\text { were developed by Brun and } \\
\text { Dugas; Paquet et al. [30, 31]. }\end{array}$ & $\begin{array}{l}\text { This term is defined as employees' perceptions of the degree to which their } \\
\text { efforts are acknowledged through a constructive reaction stemming from a } \\
\text { judgment of the employee's contribution as a matter of work practices, and } \\
\text { of personal investment and mobilization [34]. }\end{array}$ \\
\hline Appreciation & 10 & $\begin{array}{l}\text { The measures for } \\
\text { appreciation were developed } \\
\text { by Eisenberger et al. [32]. }\end{array}$ & $\begin{array}{l}\text { This phrase is defined as the degree to which employees believe that the } \\
\text { organization values their contribution and cares about their well-being [32]. } \\
\text { Sometimes this can be in form of organizational support. }\end{array}$ \\
\hline Self-esteem & 10 & $\begin{array}{l}\text { The measures for } \\
\text { Self-esteem were developed } \\
\text { by Pierce et al.. }\end{array}$ & $\begin{array}{l}\text { This is termed as feelings of worth or value employees feel within their } \\
\text { workplace Payne; Pierce et al.. }\end{array}$ \\
\hline Job Satisfaction & 10 & $\begin{array}{l}\text { Job Satisfaction was } \\
\text { measured using six items } \\
\text { developed by Brayfield \& } \\
\text { Rothe [33]. }\end{array}$ & This term is described as the degree of affective attachment to the job [35]. \\
\hline Job Performance & & $\begin{array}{l}\text { The measures for Job } \\
\text { Performance were developed } \\
\text { by Paterson. }\end{array}$ & $\begin{array}{l}\text { The term Job performance is known as a scalable action, behavior and } \\
\text { outcomes that employees engage in or bring about that are linked with and } \\
\text { contribute to organizational goals, Viswesvaran. }\end{array}$ \\
\hline
\end{tabular}

variables in this study. This will followed with presentation of the inferential statistics based on examination of each hypothesis formulated for the research.

\section{Conclusions}

Based on previous studies exploration, it appears that many studies have not been done on appreciation as a motivating factor. Thus, this study anticipate that combining these two concepts together (Recognition and Appreciation) will further add to body of knowledge by providing useful and up to date literature for future researchers. Study has established in the past that one of the best ways to gain and infuse commitment into an employee is through simple acknowledgement of that effort immediately. This study also expected that the findings of this present study could offer guiding principle in developing a suitable and applicable intrinsic rewards system for information technology organizations and other establishments.

\section{Acknowledgments}

The author would like to express sincere appreciation to Universiti Teknikal Malaysia Melaka (UTeM) sponsored by Zamalah Scheme.

\section{References}

[1] Nghi, T., and Yecenia, R. O. 2007. Rewarding and Recognizing Employees: How IT Professionals in Sweden and in Finland are Motivated and Prefer to be Rewarded. Blekinge Institute of Technology, Ronneby, Sweden Master Thesis in Business Administration.

[2] Manoko, M. M. 2011. Employee Fairness Perceptions of a Performance Management System, Master Thesis Industrial and Organizational Psychology University of South Africa.

[3] Aniruddha, L., and Ralsi, S. 2012. Rewards and Recognition: Make a difference to the Talent in Your Organisation. Edenred (India) Private Limited \& Great Place to Work Institute, India.

[4] Cokins, G. 2009. Performance Management: Integrating Strategy, Execution, Methodologies, Risk and Analytics. New Jersey: Wiley.

[5] Kelli, B. 2012. A Study of Motivation: How to Get Your Employees Moving, Thesis Indiana University.

[6] Nelson, B. 1994. 1001 Ways to Reward Employees. New York: Workman Publishing.

[7] Achieve Global 2003. Giving Recognition. Achieve Global Facilitator Guide. Tampa, Florida, USA: Achieve Global Corporate Headquarters (Accessed 10th May, 2016).

[8] Daniel, T., and Metcalf, G. 2005. Employee Recognition: Selling, Implementing and Communicating the Program. American Society for Training and Development HR White Papers.

[9] Theresa, L. S. 2006. The Impact Recognition has on Employees in the Human Resource Department at Bemis Company, Inc. Master Research Paper University of 
Wisconsin-Stout.

[10] Paul, W. 2016. “Appreciation at Work Training and the Motivating by Appreciation Inventory: Development and Validity.” Strategic HR Review 15 (1): 20-4.

[11] O’Neill, J. 2009. Employee Retention: The Real Reasons Employees Leave Organizations and How to Stop Them.

[12] Ajila, C. O. 1997. Job Motivation and Attitude to Work as Correlates of Productivity among Workers in Manufacturing Companies in Lagos State. Nigeria. Unpublished Ph.D. Thesis submitted to the Department of Psychology O.A.U Ile-Ife Osun State, Nigeria.

[13] Seligman, M. E. P., and Csikzentmihalyi, M. 2000. "Positive Psychology." American Psychologist 55 (1): 5-14.

[14] Seligman, M. 1998. "Building Human Strength: Psychology’s Forgotten Mission.” APA Monitor 29 (1).

[15] Ebong A. P. 2011. "Assessing the Role of Work Motivation on Employee Performance”, C-Level Thesis Umeå School of Business and Economics.

[16] Kreitner, R. 1995. Management. 6th ed. Boston: Houghton Mifflin.

[17] Buford, J. A., Bedeian, A. G., and Lindner, J. R. 1995. Management in extension. 3rd ed. Columbus, Ohio: Ohio State University Extension.

[18] Higgins, J. M. 1994. The management challenge. 2nd Ed. New York: Macmillan.

[19] Reuben, M. B., and David, A. K. 1986. "The Moderator-Mediator Variable Distinction in Social Psychological Research: Conceptual, Strategic, and Statistical Considerations." Journal of Penality and Social Psychology 51 (6): 1173-82.

[20] Cohen, J., and Cohen, P. 1983. Applied multiple regression/correlation analysis for the behavioralsciences (2nd Ed.). Hillsdale, N J: Erlbaum.

[21] Herzberg, F. 1968. One more time: How do you motivate employees? Harvard Business Review 53.

[22] Maslow, A. 1943. "A Theory of Human Motivation.” Psychological Review 50: 370-90.

[23] Sekaran, U., and Bougie, R. 2010. Research Methods for Business, 5th Ed. India: John Wiley \& Sons, Ltd.

[24] Sekaran, U. 2007. Research Methods for Business: A Skill-Building Approach (5th Edn.) USA: John Wiley \& Son, Inc.

[25] Rahman B. H. 2014. Antecedents of Organizational Commitment among Engineers at Tenaga Nasional Berhad, Unplished $\mathrm{PhD}$ Thesis International Islamic University Malaysia.

[26] Israel, G. D. 1992. Determining Sample Size. University of Florida IFAS Extension PEOD6.

[27] Neuman, W. L. 2006. Social Research Methods, Qualitative and Quantitative Approaches, (6th Ed.).
Pearson International. Pearson Education Inc. USA.

[28] Blanche, M. T., Durrheim, K., and Painter, D. 2006. Research in practice. (2nd Ed.). Cape Town: UCT Press.

[29] Steve, C. B. 2011. IT Staff Turnover Intentions, Job Modification, and Effects of Recognition at Large Public Higher Institutions.

[30] Brun, J. P., and Dugas, N. 2005. "Employee Recognition: Analysis of a Meaningful Concept.” Gestion 30 (2): 79-88.

[31] Paquet, M., Gavrancic, A., Courcy, F., Gagnon, S., and Duchesne, M. A. 2011. "Recognition Practices at Work: A New Psychometric Measure and Implementation Guidelines." The International Journal of Knowledge, Culture and Change Management 10 (12): 1-16.

[32] Eisenberger, R., Huntington, R., Hutchinson, S., and Sowa, D. 1986. "Perceived Organizational Support." Journal of Applied Psychology 71: 500-7.

[33] Brayfield, A. H., and Rothe, H. F. 1951. "An Index of Job Satisfaction.” Journal of Applied Psychology 35 (5): 307-11.

[34] Paquet, M., Gavrancic, A., Gagnon, S., and Duchesne, M. A. 2011. Essential Practices of Recognition at Work: Nature and Measurement (p. 15). Montreal: Centre for Research and Intervention Health Organizations McGill University Health Centre. Retrieved from http://scholar.googleusercontent.com/scholar?q=cache:e6 Sycb_4wLYJ:scholar.google.co/+Pratiques+essentielles+ de+la+reconnaissance+au+travai:+Nature+et+mesure\&hl =en \&as_sdt 0, 11 (Accessed 10th May, 2016).

[35] Tett, R. P., and Meyer, J. P. 1993. "Job Satisfaction, Organizational Commitment, Turnover Intention, and Turnover: Path Analyses based on Meta-analytic Findings.” Personnel Psychology 46: 259-93.

[36] Chapman, G., and White, P. 2011. The 5 Languages of Appreciation in the Workplace, Northfield Press, Chicago, IL.

[37] Gallup 2014. Survey Findings: Employee Engagement, available at: www.gallup.com/poll/181289/majority-employees-not-en gaged-despite-gains-2014.aspx (Accessed 10th May, 2016).

[38] Globoforce 2011. "SHRM Survey Findings: Employee Recognition Programs”, available at: http:/go. globoforce.com/5-KEY-TRENDS.html?_kk1bac917d-a8 68-4038-a28e-8a89344601f2\&_kt9385968624 (Accessed 10th May, 2016).

[39] Lindner, J. R. 1998. "Understanding Employee Motivation.” Journal of Extension 36 (3): 1-8. Available: http://www.joe.org/joe/1998june/rb3.html.

[40] About TM/Corporate Information www.tm.com.my/ (Accessed 10th May, 2016). 